\title{
Natural Hazards and the press in the western Mediterranean region
}

\author{
M. Llasat-Botija ${ }^{1}$, M. C. Llasat ${ }^{1}$, and L. López ${ }^{2}$ \\ ${ }^{1}$ GAMA, Department of Astronomy and Meteorology, University of Barcelona, Spain \\ ${ }^{2}$ Laboratory for Atmospheric Physics, University of León, Spain
}

Received: 28 February 2007 - Revised: 19 June 2007 - Accepted: 9 July 2007 - Published: 30 July 2007

\begin{abstract}
This study analyses press articles published between 1982 and 2005 in an attempt to describe the social perception of natural hazards in Catalonia. The articles included in the database have been classified according to different types of risk. In addition, the study examines the evolution of each type of risk in the press coverage during the study period. Finally, the results have been compared to data provided by insurance companies with respect to compensations paid out for damages. Conclusions show that floods are the most important natural hazard in the region, but that the number of headlines for each event is greater in the case of snowfalls and forest fires. Factors such as the season of the year, the proximity of the affected region to the capital, the topical issues at the time, and the presence of other important news must be considered when the impact in the press is analysed.
\end{abstract}

\section{Introduction}

After droughts, floods are the most important natural hazard in Mediterranean countries, followed by windstorms and hailstorms. A report presented by the European Union on 13 October 2003 in Dresden stated that in Europe the countries most affected by floods in recent years were France (22\% of the total in Europe) and Italy (17\%). An illustrative example is the flood on 8-9 September 2002 in the Gard (PACA region, France), which caused 23 deaths and damage amounting to $€ 1200 \mathrm{M}$ (Legrand et al., 2003). The insurance companies (CCS, Consorcio de Compensación de Seguros) paid out $€ 1574530945$ for flood damage between 1971 and 2002, a sum that amounts to $78.86 \%$ of the total paid out in that period (Llasat, 2004).

Correspondence to: M. C. Llasat

(carmell@am.ub.es)
The same report found that the highest number of casualties caused by floods was registered in Italy (38\%), followed by Spain (20\%) and France (17\%). In Spain in the second half of the 20th century there were approximately 2200 deaths due to floods, and damage of over $301 \mathrm{~m}$ per year. According to the Spanish Ministry of the Environment, floods are the natural phenomenon that caused most casualties in Spain between 1995 and 2004, with 229 deaths (31\% of the total), followed by sea storms (24\%) and atypical cyclonic storms $(18 \%)$.

In Catalonia floods are the natural risk that causes the greatest damage. Catalonia has suffered eleven devastating floods since 1971 (1971, 1977, 1982, 1987, 1988, 1989, 1994 and 2000), sometimes two in the same year. Another 24 extraordinary floods must be added to this number, as well as 24 ordinary floods (Llasat et al., 2003), which in some cases caused casualties too.

The present paper approaches the study of the social perception of natural hazards in Catalonia via an analysis of press articles on the topic between 1982 and 2005. The study describes the classification of the articles and the type of database built up. The articles were classified according to the type of risk, and the evolution of this risk over time was assessed. Finally, the paper compared the data with the compensations paid out by the insurance companies.

\section{Press database}

The GAMA team (Meteorological Hazards Analysis Team) at the University of Barcelona has compiled press news related to natural risks published since 1982 in Catalan newspapers. More than 2300 articles for the period 1982-2005 have been analysed in this study.

The articles were entered into an ACCESS database (Press database) with more than ten fields covering headline, key words, type of risk, place of event, newspaper, date of event,

Published by Copernicus Publications on behalf of the European Geosciences Union. 
Table 1. Topic classification used in the database.

\begin{tabular}{llc}
\hline Topic & Description & Code \\
\hline Floods & Floods, landslides & 1 \\
Storms & Storm, sea storm, wind storm, tornado, hurricane, waves, sand storm & 2 \\
Snow and cold waves & Snowfalls, cold wave, snow slide & 3 \\
Agro-meteorological risks & Frost, hail, drought, heat wave, fires & 4 \\
Sustainable development & Pollution, bioclimatology, climate change, ozone layer, historical series, energy, environment & 5 \\
Alert chain & Training, forecasts, statistics, alerts, television, civil engineering & 6 \\
Others & Earthquakes, volcanoes & 7
\end{tabular}

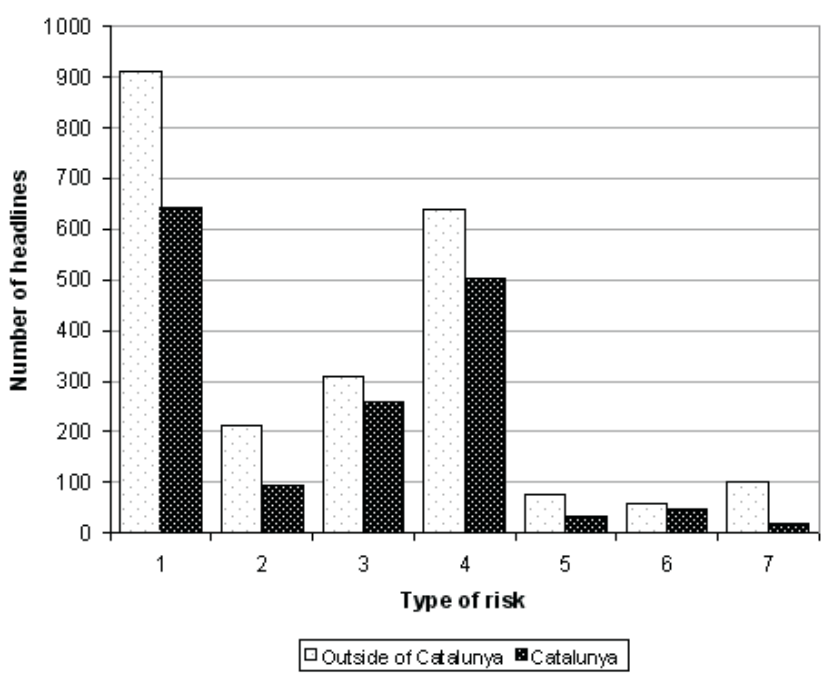

Fig. 1. Number of articles classified by type of risk from 1982 to 2005.

publishing date, page, etc. It is necessary to emphasize that for a single event, for example a flash flood, there can be several headlines because it may have been covered by several media or for several days. Because of this, in this paper we will distinguish between "events" and "headlines". The articles were classified into seven groups or types, as shown in Table 1. This database provides data for various types of analyses, such as the quantitative evaluation of the impact of each risk, or the evolution in the treatment of each type of risk by the press during the study period.

\section{Assessing risks from press data}

All the newspapers used were published in Catalonia. Figure 1 shows the number of articles published between 1982 and 2005 , classified by topic. We can see on the one hand all the articles together, irrespective of where the event occurred, and on the other hand, those articles that refer specifically to events that occurred in Catalonia. Floods represent 911 articles, 641 of which refer to episodes in Catalonia. This is

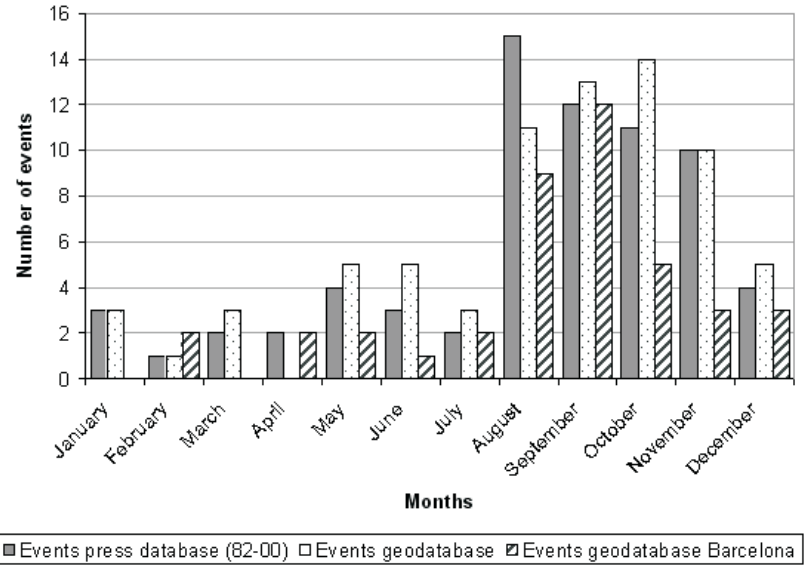

Fig. 2. Monthly distribution of flood events from the Press database for the entire Catalonia region (1982-2000) and floods identified in the INUNGAMA geodatabase for the entire Catalonia region, and for Barcelona. 1982-2000.

the type of risk that has the greatest impact in the press, followed by agro-meteorological risks (fires, basically). Next come snow and very cold spells, and lastly wind storms.

\subsection{Spatial distribution of risks}

As far as differences between floods occurring in Catalonia and elsewhere are concerned, it may be noted that articles dealing with local floods amount to $66 \%$ of the total of articles on floods. In the case of forest fires and snowfalls the percentages soar to $78 \%$ and $83 \%$, respectively. These data show that the social perception assessed using newspaper articles attaches more importance to events that occurred locally than to the events that occurred elsewhere, where the consequences do not affect that particular society directly. This interest is especially noticeable in the case of forest fires, since the loss of a natural resource such as a forest for economic uses or simply for leisure activities has a significant local impact. The same can be said of snowfalls, which cause serious problems at a local level, particularly with respect to car accidents. 


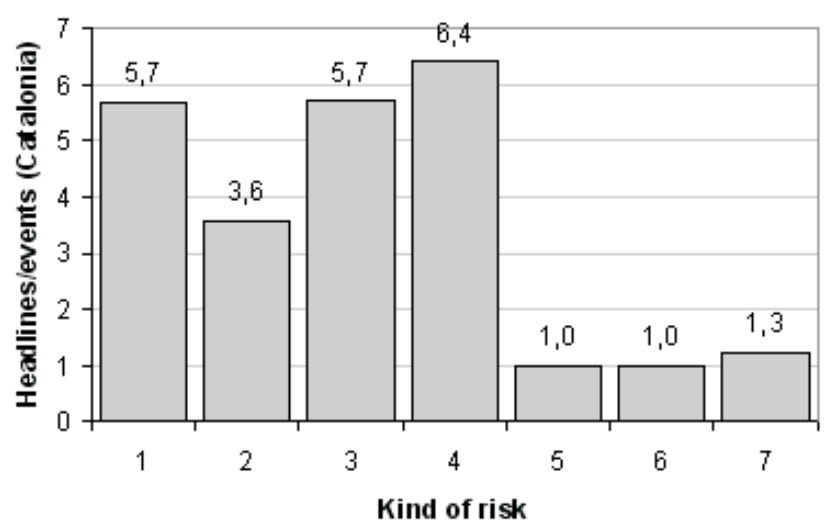

Fig. 3. Relationship between the number of headlines and the number of events registered.

Figure 2 shows that most of the events registered occurred in the city of Barcelona, where more than 3000000 of people are concentrated. This fact suggests that events occurring in or near Barcelona have a greater impact in the press because there are more people living there (50\% of the Catalan population). In addition, events occurring in Barcelona are more noticeable than events arising in other zones of Catalonia.

\subsection{Temporal distribution of risks}

The type and amount of information included in newspaper articles varies according to the time of year, the political situation, etc. Figure 2 shows the monthly distribution of flash floods according to the press, on the one hand, and according to the GAMA floods geodatabase (Barnolas and Llasat, 2007), on the other hand. The latter also took into account additional sources of information such as rain-gauge networks and radar data. A very good correlation can be observed between the two databases. One significant fact is that in the month of August the lack of interesting news leads journalists to focus more on weather phenomena, and in this month the number of articles devoted to flash floods is much higher. In contrast, in autumn the occurrence of this type of phenomenon is much higher according to the geodatabase, but these events have much less coverage in the press because other news comes back to the fore.

\subsection{Number of headlines/number of events}

The ratio "number of headlines/number of events" was calculated in order to analyse in detail the relevance of the different topics in the local press. This enables us to assess the weight given by the press to these events better than by using only the number of events. Figure 3 presents this impact index. Figure 1 showed that floods are the topic that generated most articles in the past few years, and the impact is 5.7, i.e., for each event there is an average of 5.7 articles in the press. Surprisingly, in the case of forest fires and snowfalls, the impact

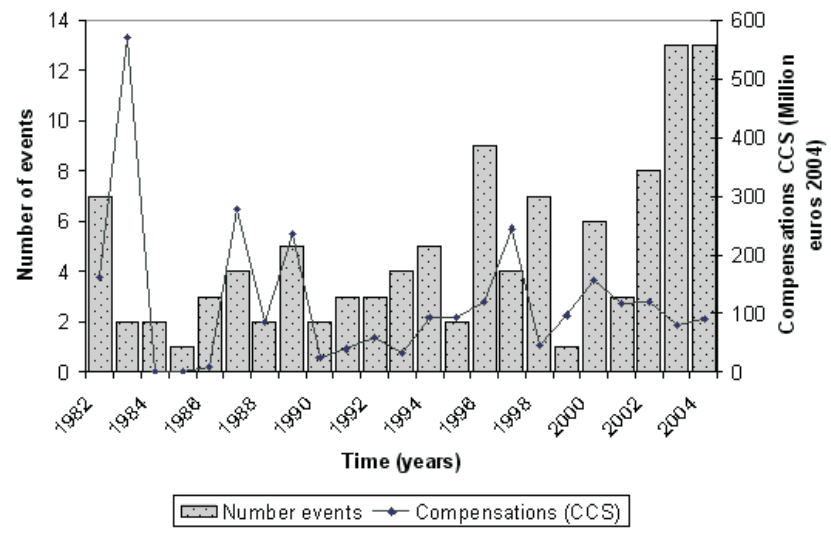

Fig. 4. Evolution of the number of floods from 1982 until today (from the press database), and the damages due to this phenomenon in Catalonia paid for by the insurance companies.

index is 5.7 and 6.4, respectively. This increase is probably due to the lower frequency of snowfalls and forest fires, and, on some occasions, to their great societal or ecologic impact when they do occur.

We must be cautious, however, when drawing conclusions from these data. Forest fires occur mainly in summer, a season when political news is much less important. In addition, fires are a type of risk that may last a long time and can be followed by the press over several days, and this contributes to explain an increase in the number of articles per event.

\subsection{Evolution of risks: floods and droughts}

Some authors use exclusively economic data to assess the social perception of natural risks (Olcina Cantos and AyalaCarcedo, 2002). Figure 4 shows the evolution of the number of events published on floods in Catalonia and the evolution of the compensations paid by the CCS over the same period of time. The correlation found between press data and economic data was not significant in this case. This is an interesting result because the results vary depending on the source of information. There are an increasing number of studies assessing risk perception through new social indicators, such as surveys (Brilly and Polic, 2005) or the number of calls received by emergency services (Petrova, 2004, 2005).

Finally, Fig. 5 shows the number of articles on droughts in Catalonia since 1982. In 2005, there were 184 articles. Lozano (2003) argues that our modern society disseminates information about catastrophes by saturating all information channels available, thus turning exceptional events into common events. In 2005 this was the case of the articles on droughts. When there is this level of saturation, the information on natural phenomena does not really help to understand them. 


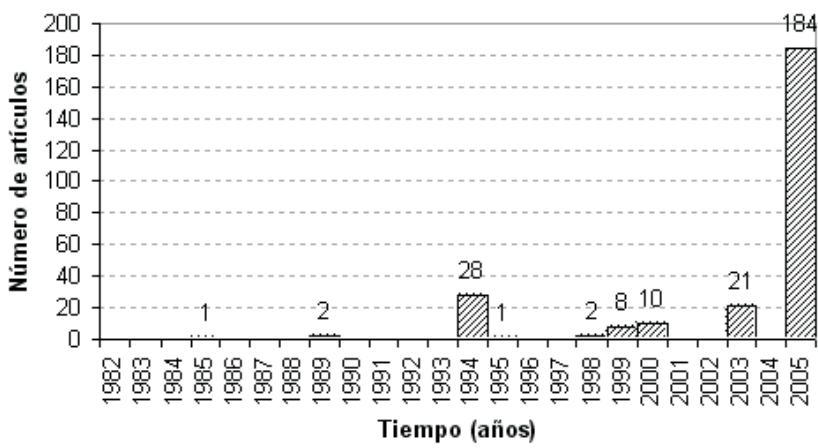

Fig. 5. Evolution of the number of articles on droughts.

\section{Conclusions}

Mediterranean countries are usually affected by natural hazards occurring every year, leading to the loss of human lives as well as considerable economic harm. According to previous studies, floods are the natural phenomenon that caused the greatest damage and casualties in this region, although in some specific countries other natural risks can hold first position in the ranking (i.e. forest fires or hail). However, experience shows that the social perception of the importance of natural hazards can be different from that shown by the objective data. This paper has explored the social perception of natural hazards in the northeast of Spain, via an analysis of press articles on the topic between 1982 and 2005.

The conclusions of this research point to the floods as the most significant natural risk in Catalonia and the oneattracting the greatest news coverage. However, forest fires, droughts and snowfalls are risks with a broader coverage per event or stronger impact. This fact is mainly due to the higher frequency of flood events that decreases the impact in the press of each episode, as well as the season of the year during which they arise. Floods are mainly recorded in autumn, when political and social activity is an important source of news. On the contrary, forest fires occur mainly during the holiday season, when the amount of news is smaller than in the rest of the year. As a consequence, forest fires are perceived by some people as the most dangerous and frequent natural hazard in the region. Snowfalls are not very frequent in the region; consequently, preventive measures and warning systems were not so highly developed as in the case of floods and forest fires (after the last great snowfalls a new warning system called "NEUCAT" was developed). Then, when an event has occurred, it has blocked all the activity in some parts of the region, making an important social impact.

The study revealed the important influence of location in the coverage of an event by the press. Events that affected the capital of Catalonia, one of the most densely populated areas, have the largest impact, although they may be considered a minor hazard. A similar influence can be observed in the monthly distribution of events. During the month of August the lack of interesting news leads journalists to focus more on weather phenomena. Besides the strong impact of forest-fire news, in this month the number of articles devoted to flash floods is higher than in autumn, when the maximum number of floods is recorded. In contrast, in autumn the occurrence of this type of phenomenon is much higher according to the geodatabase, but these events have a much smaller impact in the press because other news is returning to the forefront. For this reason, the monthly evolution of floods observed on the basis of the objective flood database is at variance with the evolution obtained from the press.

Finally, the correlation found between press data and economic data was not significant in this case. These factors lead to a non-linear relationship between economic losses and

the social impact across the press, as well as between the magnitude of the event and this social impact.

Acknowledgements. The present study was supported by the European Project FLASH (FP6-2005-Global-4 (no. 036852). It was conducted within the framework of the WMO Project MEDEX. Our acknowledgement to M. Angel Prat and M. Barnolas for their kind collaboration.

Edited by: P. Alpert, H. Saaroni, and E. Heifetz

Reviewed by: two anonymous referees

\section{References}

Barnolas, M. and Llasat, M. C.: A flood geodatabase and its climatological applications: the case of Catalonia for the last century, Nat. Hazards Earth Syst. Sci., 7, 271-281, 2007, http://www.nat-hazards-earth-syst-sci.net/7/271/2007/.

Brilly, M. and Polic, M.: Public perception of flood risks, flood forecasting and mitigation, Nat. Hazards Earth Syst. Sci., 5, 345355, 2005, http://www.nat-hazards-earth-syst-sci.net/5/345/2005/.

Legrand, P., Brugnot, G., and Baumont, G.: Rétour d'experience des inondations de septembre de 2002 dans les départaments du Gard, de l'Hérault, du Vaucluse, des Bouches de Rhône, de l'Ardèche et de la Drôme, Contribution du Groupe d'Appui et d'expertisse scientifique, CD-ROM, 2003.

Llasat, M. C., Rigo, T., and Barriendos, M.: The 'Montserrat-2000' flash-flood event: a comparison with the floods in the Northeastern Iberian Peninsula since the 14th centur, Int. J. Climatol., 23, 453-469, 2003.

Llasat, M.C.: La vulnérabilité en Catalogne, Colloque SHF, Crues Méditerranéennes, Nimes, juin 2004 (Publications S.H.F.), 2934, 2004.

Lozano Ascencio, C.: Libertad de expresión y Sociedad del Riesgo, Congreso Pasado, Presente y Futuro de la Libertad de Expresión, Universidad San Pablo-CEU, Madrid, 26-28 Noviembre 2003.

Olcina Cantos J. and Ayala-Carcedo, J.: Riesgos naturales, Barcelona, Ariel, Ciencia, 2002.

Petrova, E.: Social and economic factors of the natural risk increasing: estimation of the Russian regions, Nat. Hazards Earth Syst. Sci., 4, 243-248, 2004, http://www.nat-hazards-earth-syst-sci.net/4/243/2004/. 
Petrova, E: Natural hazards and technological risk in Russia, The relation assessment, Nat. Hazards Earth Syst. Sci., 5, 459-464, 2005,

http://www.nat-hazards-earth-syst-sci.net/5/459/2005/. 